\title{
LA IGLESIA ROMÁNICA DE SAN MICHELE DE MURATO EN CÓRCEGA: HIPÓTESIS DE RESTITUCIÓN DEL CAMPANARIO DE FACHADA POR LA DOCUMENTACIÓN HISTÓRICA Y GRÁFICA ANTERIOR A LA RESTAURACIÓN
}

\author{
Claudia Sanna ${ }^{1}$
}

\begin{abstract}
RESUMEN
La iglesia de San Michele de Murato, en Córcega noreste es un ejemplo hermoso de construcción románica en bicromía, construida por oficiales Pisanos, alrededor de la segunda mitad del siglo XII. Su particularidad principal, además de la cantidad increíble de partes esculpidas, es la de tener un campanario elevado delante de la fachada, formando un pórtico abierto sobre tres lados. El campanario, que tenía al principio una altura de alrededor de 11 metros, torpemente y gratuitamente fue sobrealzado de 5 metros, alrededor de la segunda mitad del siglo XIX, desnaturalizando las dimensiones del edificio entero. Gracias a la comparación con dibujos y estampas anteriores de la transformación, sin embargo podemos reconstruir el aspecto original y volver a apreciar las dimensiones primitivas.
\end{abstract}

Palabras clave: Córcega, Iglesia románica, Bicromía, Campanario, Prosper Mérimée, Restauración.

\begin{abstract}
The Church of San Michele di Murato, in northeastern Corsica is a beautiful example of Romanesque construction in bichrome work, built by Pisan workers around the second half of the XII century. His main particularity, in addition to the incredible amount of graven parts, is to have a bell tower risen in front of the façade, forming a portico open on three sides. The bell tower, that had originally a height of around 11 meters, was awkwardly and gratuitously raised by 5 metres around the second half of the XIX century, denaturalizing the proportions of the whole building. Thanks to the comparison with sketches and prints prior to the transformation, we can however reconstruct the original aspect and so return to appreciate the primitive proportions.
\end{abstract}

Fecha de recepción: 30 de octubre de 2009. Fecha de aceptación: 19 de enero de 2010

1 Università degli Studi di Cagliari, Italia. Email: morganthewitch@ hotmail.com. 
Key words: Corsica, Romanesque church, Bichrome decoration, Bell-tower, Prosper Mérimée, Restoration.

Los estudios históricos, arqueológicos e histórico-artísticos sobre la Córcega Medie$\mathrm{val}^{2}$ son hechos muy difíciles por la persistencia de un vacío historiográfico y documental relativo a los siglos que van desde finales de la Tarda Antigüedad hasta toda la Edad Media. La historiografía moderna de Corcega se ha limitado, en efecto, a dar dignidad de fe a las leyendas y los cuentos populares que se transmitieron desde siglos, sin efectuar sobre de ellos una revisión crítica, y perpetuando aquellos lugares comúnes que sólo las investigaciones arqueológicas, paleografico-diplomatisticas e historiográficas de las últimas décadas están contribuyendo a demoler.

Se puede comprender como las obras sobre la historiografía artística de Córcega sean muy disminuidas: desde el primer interés ${ }^{3}$ del francés Prosper Mérimée como Inspector de los Monumentos Históricos (1840), hasta la monografía del estudioso sardo Carlo Aru sobre las Chiese Pisane di Corsica (1904) ${ }^{4}$, pasan casi setenta años; cincuenta desde la obra del Aru hasta el estudio vanguardista pero imprescindible que por fin una estudiosa de la Corcega hace sobre los monumentos paleocristianos y medievales de su isla. En el 1967 en efecto, la estudiosa Geneviève Moracchini-Mazel da a la prensa dos obras fundamentales para el estudio de la Historia del arte Medieval de Córcega: se trata de Les Eglises Romanes de Corse $e^{5}$, seguida de Les Monuments Paléochretiens de la Corse ${ }^{6}$.

En estos dos trabajos la estudiosa vierte la mole de trabajo y datos que ha recopilado y destapado en años de excavaciones y búsquedas de archivos, dotando por fin a la comunidad científica de una serie de instrumentos inestimables para el estudio y la búsqueda sobre la materia. Los dos volúmenes tienen ya más de cuarenta años de vida, y también padecen de una falta de cotejos científicos en ciertas partes, además de una impostación demasiado personal dada por la estudiosa. Dichosamente en el 2006 se da a las prensa la obra de Roberto Coroneo Chiese romaniche della Corsica, Architettura e Scultura $(X I-X I I I \text { secolo })^{7}$, que tiene el mérito de hacer orden sobre los estudios recientes sobre el Románico en Córcega y en general su Edad Media.

Las cartas del papa Gregorio Magno ${ }^{8}$ que, a finales del siglo VI, se interesa de la isla caída en un casi total abandono civil y religioso, nos ofrecen las únicas noticias, antes de que Córcega precipite en el siglo VIII sec. en la oscuridad más absoluta, presa probablemente de los longobardos. Durante casi cuatro siglos la Historia y sus protagonistas parecen olvidarse de esta isla, que es abandonada a las repetidas correrías de los piratas sarracenos. Sólo el papado la recordará por un momento y sin embargo será para reivindicarla a su Patrimonium en el momento del nacimiento del Estado Pontificio. En los

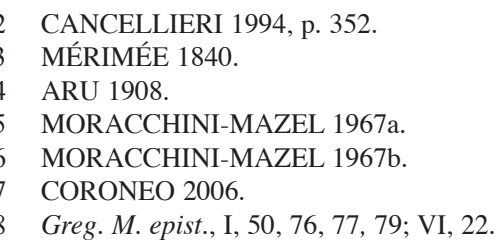


siguientes dos siglos, se suceden vanas tentativas de poner remedio a la invasión árabe sobre las rutas mediterráneas, y solo hasta principios del año Mil un duro golpe es dado a la flota musulmana por parte de las repúblicas marineras de Pisa y Génova; las aguas se libran y Córcega puede asomarse sobre el panorama histórico internacional, mientras quién está de la otra parte del Tirreno por fin se da cuenta de aquella isla olvidada. Lo primero en hacerlo es, en 1079, papa Gregorio VII, (quizás escarmentado de las obras de su homónimo y santo predecesor), que decide poner la isla bajo el ala de la Santa Sede y encarga al obispo de Pisa Landolfo de restablecer la autoridad papal nombrándolo vicario apostólico: de hecho entrega Córcega en las manos de la República pisana marcando su suerte para los dos siglos que vienen. Pisa se encuentra por lo tanto con el deber de decidir las suertes de la isla y a gobernar sobre una miríada de señorones locales violentos y guerreristas. Pero ella es a su máximo resplandor tanto político como cultural: la Catedral de Santa Maria Assunta es la maravilla del nuevo estilo románico, modelo inspirador por todos los otros edificios religiosos romanicos, y tanto los religiosos que los laicos pisanos sabían que la construcción de las iglesias es señal del progreso de la civilización cultural de una región.

Córcega será invertida de este fervor arquitectónico y cultural y verá surgir sobre su tierra decenas y decenas de iglesias románicas, es cierto que no a la altura de las fábricas de ultramar pero señal indeleble de lo ocurrido en aquella Edad de Oro, contemplada como memorable y maravillosa por parte de los cronistas modernos, que ha sido la dominación pisana de la isla. Papa Urbano II en 1092 eleva la diócesis de Pisa a arzobispado 9 con poderes metropolitanos sobre Córcega, por lo tanto con la facultad del arzobispo de nombrar a los obispos de la Isla. A los principios del siglo XII la isla cuenta cinco diócesis (Aleria) Mariana, Ajaccio, Sagona, Nebbio, y unos 70 pievi (parroquias). El prestigio de la Iglesia de Pisa es a la cumbre: 1119 ve la consagración de la primera iglesia románicapisana sobre el suelo de Corcega, la Catedral de S. Maria Asumida sede de la diócesis de Mariana, conocida también como la "Canonica"10, en la parte Norte-oriental de la isla. Desde esta fecha y durante los siglos XII y XIII, las fábricas romanicas se suceden a un ritmo cerrado. De algún año más tarde, pero siempre dentro de la mitad del siglo XII es la otra gran catedral, aquella de Santa Maria Asumida de Saint-Florent ${ }^{11}$, en la diócesis del Nebbio. Las catedrales de Mariana y Nebbio constituyen los edificios de mayores dimensiones del románico de Corcega; las restantes fábricas románicas de la isla, la mayor parte constituidas por las pievi, son de modestas dimensiones, de una nave y con ábside a Este, pero siguen teniendo como modelo los edificios de Pisa, la Catedral en primis, y de Toscana generalmente, declinados en una manera local sobria, con rasgos pobres, por la endémica pobreza de material lapideo de corte. Entre estas fábricas sobresale, por

9 UGHELLI, Italia Sacra, III, 369.

10 VALERY 1837, pp. 314-315; MÉRIMÉE 1840, pp. 96-107; ARU 1908, pp. 38-51; MORACCHINIMAZEL 1967a, pp. 84-94, 217-218; MORACCHINI-MAZEL 1967b, pp. 83-110; CORONEO 2006, pp. 99-108 e 112-115.

11 VALERY 1837, pp. 55-56; MÉRIMÉE 1840, pp. 121-125; ARU 1908, pp. 62-71; MORACCHINIMAZEL 1967a, pp. 95-102, 259; MORACCHINI-MAZEL 1972, pp. 125-129; Daniel Istria, in Corsica Christiana 2001, 2, p. 29, sch. 46; CORONEO 2006, pp. 109-110 e 136-140. 
colores y decoración, la iglesia de San Michele de Murato ${ }^{12}$. El edificio, que pertenece al ayuntamiento de Murato, en el departamento de la Haute-Corse, Alta Córcega, (está lejos $18 \mathrm{~km}$ de Saint-Florent y 23 de Bastia), más que por la policromía y la torre de fachada, se caracteriza por una exuberancia de elementos escultóreos que no tiene comparación en ningún otro edificio románico de la isla. Estas características hacen de San Michele de Murato, con la Canonica de Mariana, el edificio románico más conocido de Córcega, pero esta popularidad se estrella con el vacío documentario que hace de él uno de los edificios más oscuros y desconocidos también científicamente.

La primera atestación de la iglesia y del título de San Michele ${ }^{13}$ se encuentra entre uno de los documentos del Cartulario del archivo de la Cartuja de Calci ${ }^{14}$, cerca de Pisa, que atañen la vida y los asuntos del monasterio de S. Gorgonio de la isla de Gorgona con las relativas posesiones en Córcega y en el condado pisano. Uno de estos papeles, fechado al 31 de marzo del $1137^{15}$, certifica algunas donaciones que Landolfo episcopus Nebiensis, (post 1137 - post 1144), hace al monasterio de San Gorgonio. El acto es redactado en civitatem Nebio, el actual Saint-Florent, de Guilielmus notaruis apostolices sedis en la presencia de varios testigos, entre los que aparece el "presbítero Angilielmo de sancto Michaele de Lorecta et Ildebrandus de Lorecta et filio su Saracino"16. Sancto Michaele de Lorecta no es otro que la iglesia de San Michele de Murato, ella que fue guiada en aquel tiempo por un presbiter Angilielmo.

En el año 1144 son redactados otros cuatro documentos del archivo de Calci ${ }^{17}$, todos con idéntica datación al 31 de marzo, (la misma del documento fechado pero al 1137). En estos cuatro actos, siempre redactados por el notario Guiliemo o Wuilielmus, pero esta vez bajo el obispo nebbiense Guglielmo, comparecen los mismos testigos del primer documento entre aquel presbítero Angilielmo que es en su momento llamado Angilelmi capellani de Loretta ${ }^{18}$, Angnenelmi capellani de Loretta ${ }^{19}$, Anglinelmus cappellanus de Loretta $^{20}$ y Angelelmi capellano de Loretta ${ }^{21}$. Desde la coincidencia de día y mes, indicción, testigos, además de toda una otra serie de elementos interiores a los instrumentos, se podría hipotetizar que también el primer documento fuera originariamente fechado en el año 1144 y que, o por un error de transcripción, o por una falsificación intencionada, haya sido antedatado al 1137. Sin embargo, eso no excluye que la primera atestación de la iglesia de San Michele de Murato sea de la primera mitad del siglo XII, su instalación sería de pocas décadas posterior a la catedral del Nebbio, cuya primera atestación siem-

12 VALERY 1837, pp. 49-50; MÉRIMÉE 1840, pp. 125-132; p. 102; GALLETTI 1863, pp. 115-116; ARU 1908, pp.72-84; ARU 1939, p. 94; MORACCHINI-MAZEL 1967a, pp. 132-140, 260; MORACCHINI-MAZEL 1792, pp. 167-172; MORACCHINI-MAZEL 2004, p. 274; CORONEO 2006, pp. 142-145, 154-156.

13 ISTRIA 2005, p. 114.

14 SCALFATI 1971.

15 SCALFATI 1971, n 68, pp. 164-166.

16 SCALFATI $1971, \mathrm{n}^{\circ} 68$, p. 165, líneas 37-38.

17 SCALFATI $1971, \mathrm{n}^{\circ}$ 90-93, pp. 218-227.

18 SCALFATI 1971, n 90, p. 22034.

19 SCALFATI 1971, n 91, p. 22231.

20 SCALFATI 1971, n 92, p. 2206.

21 SCALFATI 1971, nº 93, p. 22711. 
pre remonta al $1144^{22}$. Las maestranzas del San Michele de Murato, presumiblemente toscanas si no de procedencia, por lo menos de formación, se inspiraron en modelos del románico pisano, luqués y de Pistoya; difundieron, en particular, el empleo de la obra bicroma, a causa del clamor suscitado por la fábrica rainaldiana de la Catedral de Pisa, enseguida después de la mitad del siglo XII. Sin embargo, en el condado de Pistoya, ella toma exasperadamente carácteres coloristas con la actividad de Gruamonte, que se formó en la fabrica pisana de Guglielmo, aunque tuvo los primeros ejemplos alrededor de la mitad del siglo en las reconstrucciones del Sant'Andrea ${ }^{23}$ y el San Bartolomeo in Panta$n o^{24}$. La influencia de los ejemplos toscanos puede ser también mediada por la experiencia de las maestranzas que construyeron la serie de edificios románicos en obra bicroma en la cercana Cerdeña, los que tienen como arquetipo el cumplimiento de la iglesia de San Pietro de Sorres a Borutta, (segunda mitad siglo XII) ${ }^{25}$. Estas maestranzas que obraron a Murato después de la mitad del siglo XII, erigieron, con toda probabilidad, también la iglesia de la Trinità di Aregno ${ }^{26}$ y a la Pieve di San Raineri di Pino a Montemaggiore ${ }^{27}$, en la parte Norte-occidental de Córcega. La construcción del campanario podría remontar a un período siguiente a la instalación, en cuánto ello parece obliterar al menos en parte los arquillos rampantes del frontón. Considerado sin embargo la "restauración" de finales del siglo XIX obrada sobre el campanario, por el que se ha procedido a una elevación del mismo de variados metros, esta intervención maciza y no necesaria puede haber destruido porciones útiles a una lectura cronológica del edificio, mientras que ha alterado definitivamente sus proporciones.

La planta [Fig. 1] de la iglesia de San Michele de Murato [Fig. 2] se estructura en los modos usuales de la arquitectura románica, con nave única y ábside semicircular orientadas a Este, pero con la presencia original del campanario de fachada. Éste apoya sobre dos pilares cilíndricos, que forman un porche abierto sobre tres lados con arcos de medio punta decorados por cuñas en bicromia. Ejemplo único en el panorama de la arquitectura románica de Córcega, esta icnografía encuentra homólogos en toda la Península Italica y en Europa en general. Al centro de la fachada se abre la entrada principal del edificio. Una entrada secundaria esta ubicada en el lado sur, mientras dos óculos en fachada y tragaluces arqueados con derrame en el orden de dos por lado, dan luz a la nave. Un tragaluz con derrame se abre tambien al centro del ábside.

Las dimensiones del edificio son modestas, como es para casi todas las fábricas románicas de Córcega: la nave es larga 14,45 m, por 5,55 m de ancho, con cobertura de madera; la altura está de unos $6,50 \mathrm{~m}$ por los muros laterales, y de 7,50 por las fachadas este y oeste; el campanario es de caña cuadrada, altura aproximada de $11 \mathrm{~m}$ y apoya sobre pilares de $4 \mathrm{~m}$, con capiteles chatos, por una altura total de acerca de $15 \mathrm{~m}$. La cobertura es en

22 SCALFATI 1971, n 92, pp. 223-225.

23 SALMI 1927, p. 48.

24 SALMI 1927, p. 48; MORETTI, STOPANI 1982, pp. 233-237.

25 DELOGU 1964; CORONEO 1993, pp. 96-97 sch. 20; CORONEO, SERRA 2004, pp. 169-178.

26 VALERY 1837, pp. 79; MORACCHINI-MAZEL 1967a, pp. 127-132, 342-343; MORACCHINIMAZEL 1972, pp. 173-177; Daniel Istria, in Corsica Christiana 2001, 2, p. 33, sch. 57; CORONEO 2006, pp. 142-144 e 151-158.

27 MORACCHINI-MAZEL 1967a, pp. 142-143, 264; CORONEO 2006, pp. 156-158. 


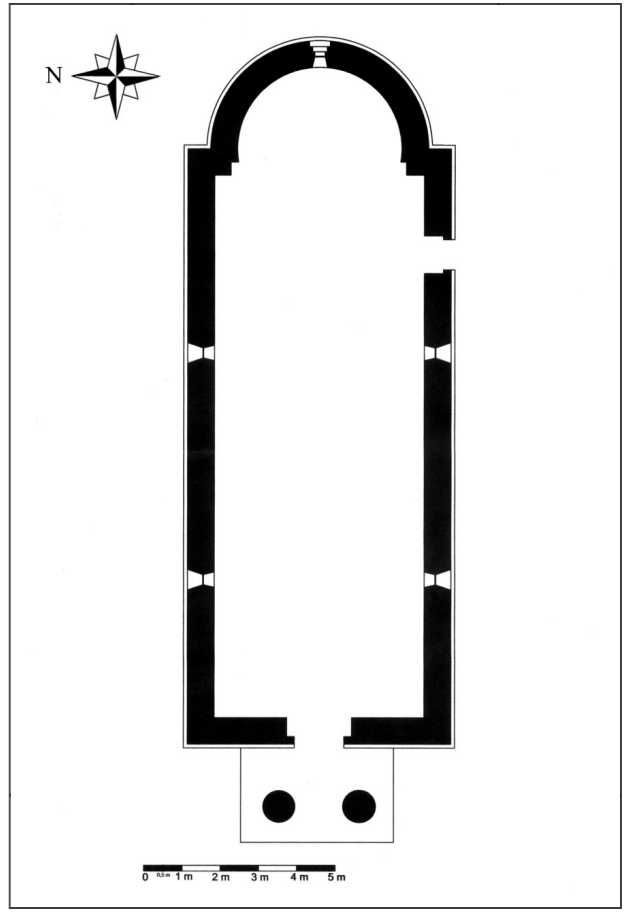

Figura 1. Iglesia Rómanica de San Michele de Murato, fachada y lado sur (mitad siglo XII).

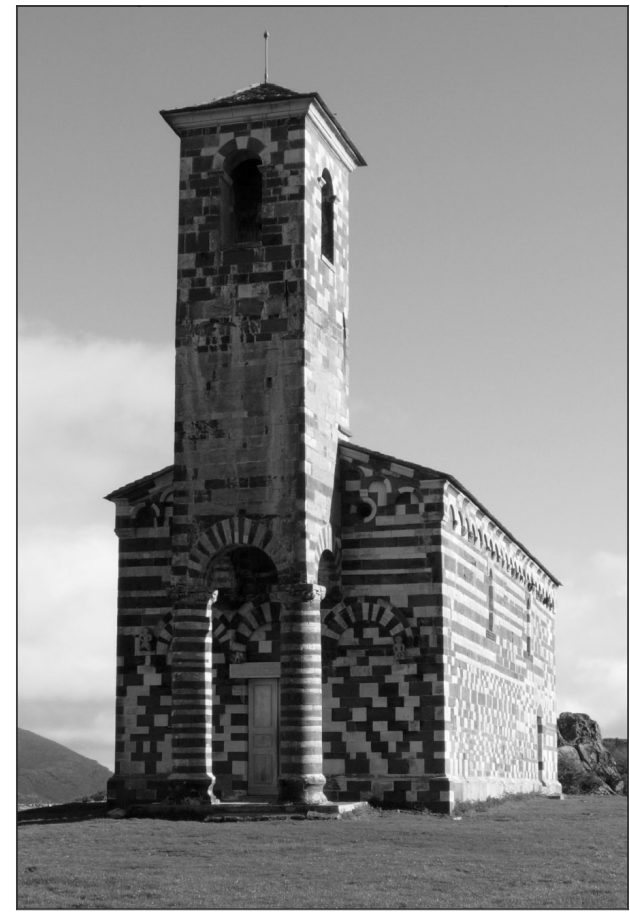

Figura 2. Plancha de la Iglesia de San Michele de Murato (mitad siglo XII).

teghie, las típicas losas de esquisto verde, piedra muy abundante en la zona usada como revestimiento por los tejados, pero ella sólo es original en el ábside, mientras en la nave es fruto de una restauración que ha podido restablecer dichosamente la armonía general de la obra. Bajo el marco del tejado se disponen arquillos a doble dintel o a arista viva, que se apoyan en ménsulas molduradas, que corren paralelas a lo largo de los frontones.

La mampostería, lisa y totalmente falta de pilastras o de parastades de ángulo, es en obra bicroma pero no es dispuesta con un orden regular: los bloques de serpentino verde del Bevinco, piedra que se encuentra en cantidad a lo largo de las orillas de este río, y de caliza blanca del Nebbio, con cuyo también ha sido construida la catedral de Santa Maria Assunta a Saint-Florent, forman en la fachada y en la parte baja del lado sur un tablero irregular, mientras que son al menos en parte presentes bandas horizontales alternativamente claras y oscuras en el lado Norte determinando un efecto coloristico sorprendente.

La irregular alternancia de color se extiende a todos los elementos estructurales y de decoro del edificio a subrayar cada elemento que lo compone. En la fachada oriental, sobre el que se enchufa la torre campanaria, se abre al centro el portal principal sin jambas, arquitrabado y con arco de descarga de medio punto formado por cuñas alternativa- 
mente verdes y blancas. A los lados de la entrada se disponen dos arcadas ciegas, también en medio punto, una por cada lado, siempre compuestas de cuñas en bicromia y que apoyan, como por el arco de la entrada, en repisas esculpidas con figuras antropomorfas y de animales en fuerte relieve. Bajo las terminales del tejado, a lo largo de las naves corren arquillos colgantes que apoyan en ménsulas molduradas y grabadas de varia manera con figuras antropomorfas, zoomorfas y vegetales, ellas también en fuerte relieve.

Sobre cada lado, dentro de una luneta, está presente un alojamiento por jofaina cerámica, ya vacío. Dos tragaluces por lado, arquivoltados y con derrame, iluminan el interior de la nave; cada uno es superado por una arquivolta cortada a hilo y ornato por esculturas en un relieve muy bajo. Lo mismo ocurre en el antetecho. En el lado sur se abre una entrada secundaria con dintel a tímpano elevado, sin jambas. Dinteles de este género se encuentran en Córcega en el San Parteo de Mariana (primer cuarto siglo XII) ${ }^{28}$, y en Cerdeña en la catedral de Santa Giusta, (post 1144) ${ }^{29}$. La fachada absidal es muy simple, también es privada de pilastras y parastades de angulo. A lo largo de las terminales del tejado corren arquillos cortados a hilo, apoyantes en mensulas cuyo relieve es tratado con una calidad mucho mayor con respecto de los de los flancos y de la fachada Oeste. Tres lunetas llevan alojamientos por jofainas cerámicas.

Bajo la mensula central se abre una ventanilla cruciforme. También el ábside es provisto de arquillos colgantes en número de siete, que se apoyan en mensulas molduradas. $\mathrm{Al}$ centro del ábside se abre un tragaluz con arquivolta a medio centro en caliza blanca decorada por taraceas verdes a cuñas y rositas. El interior del edificio es muy pobre. El ábside medieval se proyecta sobre la nave por un arco triunfal a doble abrazadera formado por cuñas en bicromia. El arco externo apoya en pilastras, siempre en bicromia, a través de estrechos capiteles cuadrangulares, impresos en decoración floral y caritas antropomorfas en los rincones, de ejecución grosera. En el centro del arco la llave es tallada con un águila con las alas abiertas. La cara del arco triunfal presenta frescos del fin del siglo $\mathrm{XV}^{30}$ que representan la Anunciación de la Virgen. Otros frescos estuvieron presentes en el cascarón absidal, pero sólo queda una lábil huella, incluso pintados fueron los pilares y en parte las paredes de la nave. De esta descripción total de la iglesia de San Michele de Murato se saca una percepción de extrema sencillez en la instalación estructural, pero avivada por la irregular y, en cuánto tal, vivaracha obra bicroma como incluso de la superabundante decoración escultórea extensa a cada elemento constitutivo del edificio, en una compleja articulación que recuerda el horror vaqui de molde árabe.

Superado el primer impacto visual debido a la extraordinaria bicromia del edificio, el ojo del observador que se encuentra frente a la iglesia de San Michele de Murato, es capturado por la grandeza del insólito campanario que se yergue delante de la fachada y casi obstruye la vista de ello. Sin embargo, a una observación total más atenta del edificio se puede notar una incongruencia que concierne las proporciones de dicha torre: ella

28 MÉRIMÉE 1840, pp. 108-111; ARU 1908, pp. 51-53; MORACCHINI-MAZEL 1967a, p. 94; MORACCHINI-MAZEL 1967b, pp. 79-89; MORACCHINI-MAZEL 1972, pp. 79-82; MORACCHINI-MAZEL 2004, pp. 281-285; CORONEO 2006, pp. 115-119, 122-123 e 135-136.

29 CORONEO 1993, pp. 68-78, sch. 11 p. 68; CORONEO, SERRA 2004, pp. 123-138.

30 ORSOLINI 2003, pp. 49-50. 
aparece demasiado elevada y maciza con respecto del resto de la iglesia, siendo alta casi el doble del muro de fachada, y hacia arriba el fuerte salto no coincide con el sosiego de las proporciones de la nave, casi acomodada sobre el plan. Si luego se detiene sobre las características de la torre, ventanas, terminales del techo, cornisa, entonces la incongruencia se convierte en error.

Esta contradicción es debida a una infeliz intervención de restauración ${ }^{31}$ ocurrida al campanario al final del siglo XIX: el campanario vino sobreelevado de unos 5 metros y fueron añadidas cuatro grandes ventanas, demasiado anchas y altas, y un tejado piramidal, empalmado a los muros a través de un enorme marco moldurado. No se tienen informaciones sobre la decisión y la puesta en acto de esta operación, no parece haber sido necesaria no más allá de que inoportuna. En efecto, en la relación provista por Prosper Mérimée al ministro del interior francés, durante su encargo de Inspector general de los Monumentos, el campanario de la iglesia de San Michele de Murato es descrito sumariamente ${ }^{32}$ y no hay comentarios sobre su estado de conservación, así que ello no preocupó al inspector y no necesitó por lo tanto de intervenciones de restauración o de seguridad.

A pesar de eso, por una razón todavía oscura, el campanario fue forzado y con ello fue comprometida la estereometría de todo el edificio. Dichosamente en cambio, podemos conocer, el antiguo aspecto de la torre de fachada por algunos testimonios gráficos dejados por artistas y viajeros que han visto la iglesia antes de la restauración y la han inmortalizado en pinturas e incisiones, de modo que podemos apreciar las correctas proporciones del edificio y arriesgar una hipótesis de restitución de su aspecto originario. Las más antiguas imágenes de la iglesia de San Michele a Murato las debemos a Pierre Thomas Le Clerc $^{33}$, dibujante francés que vivió entre el 1740 y el 1796 y que, en un viaje suyo a Córcega presumiblemente alrededor de lo penúltimo cuarto del siglo XVIII, reprodujo sobre tres acuarelas sus puntuales impresiones sobre la visita a la iglesia de Murato. Las acuarelas son actualmente conservadas a París en la Bibliothèque Nationale de France $e^{34}$, y representan, en el orden, la fachada [Fig. 3], el lado Norte del edificio [Fig. 4] y el ábside ${ }^{35}$, con abundancia de detalles, pero también con alguna concesión a la fantasía en reconducir algunas partes esculpidas de la fachada y de los flancos. El pintado figurante de la fachada, nos da enseguida la imagen de como aparecía (resultaba) el campanario originario, mucho más bajo de aquel actual, superado por un tejado a dos aguas de una sencillez extrema. La imagen siguiente, muestra la vista del mismo campanario de un lado, así se puede valorar la profundidad, que se presenta de muy inferior a aquella de la torre actual. La fidelidad de los detalles, apreciable en la correspondencia de las mensulas de las terminales del ábside con la realidad, no pone en duda el efectivo conocimiento directo del edificio de parte de Le Clerc, sin embargo, para confutar en parte esta visión, podemos confrontar sus dibujos con una incisión publicada en las Notes d'un voyage en

31 Se vea el juicio negativo dado por el Aru: ARU 1908, p.82.

32 MÉRIMÉE 1840, p. 126.

33 PINAULT SØRENSEN 2003, p. 131.

34 Paris, Bibliothèque Nationale de France, Département des estampes et de la photographie, VA 20, tomo 2, ábside (H 116802), lado sud (H 116801), fachada (H 116799).

35 MORACCHINI-MAZEL 1967a, p. 133, fig. 261; Coroneo 2006, p. 154, fig. 191. 


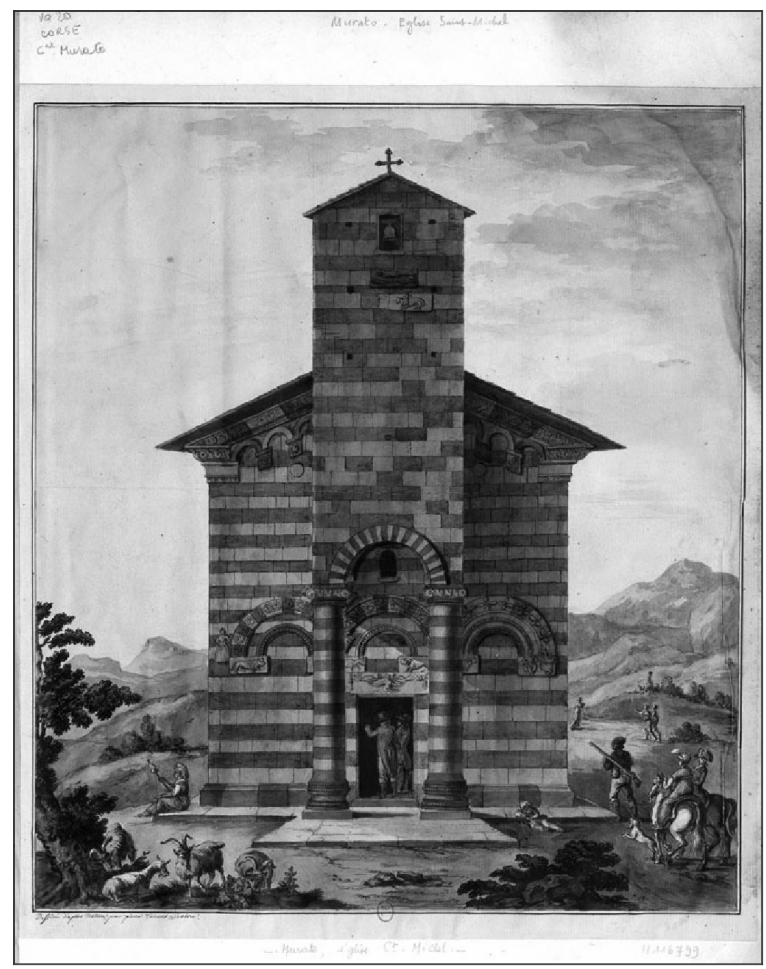

Figura 3. Pierre Thomas Le Clerc (1740c.-1796), Eglise Saint-Michel, acuarela. Paris, Bibliothèque Nationale de France, Département des estampes et de la photographie.

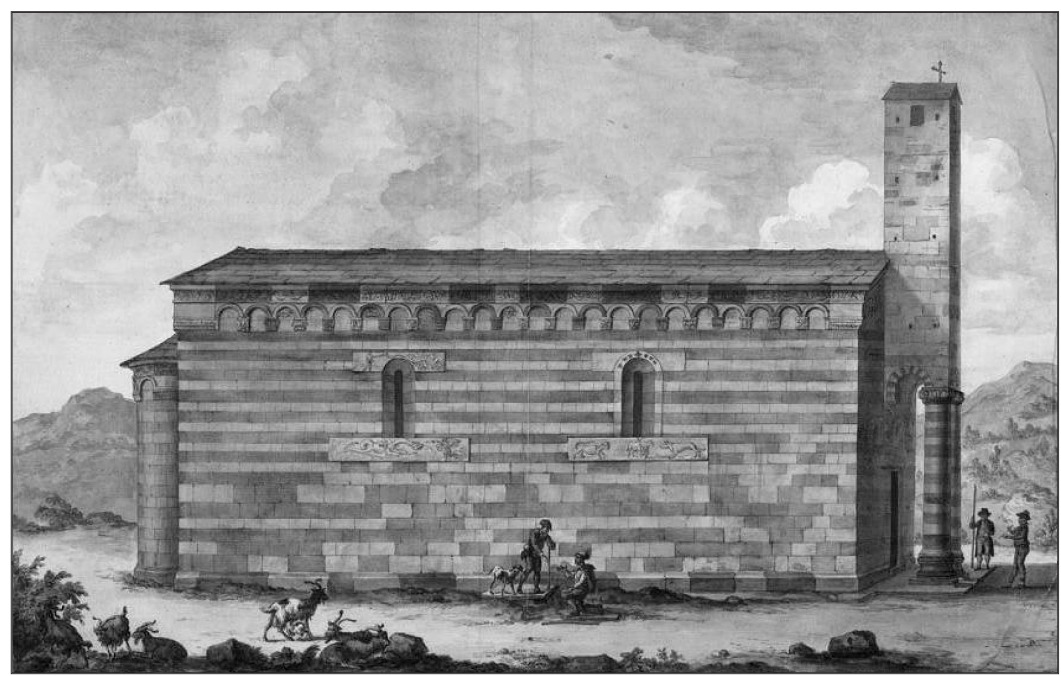

Figura 4. Pierre Thomas Le Clerc (1740c.-1796), Eglise Saint-Michel de Murato, acuarela. Paris, Bibliothèque Nationale de France, Département des estampes et de la photographie. 


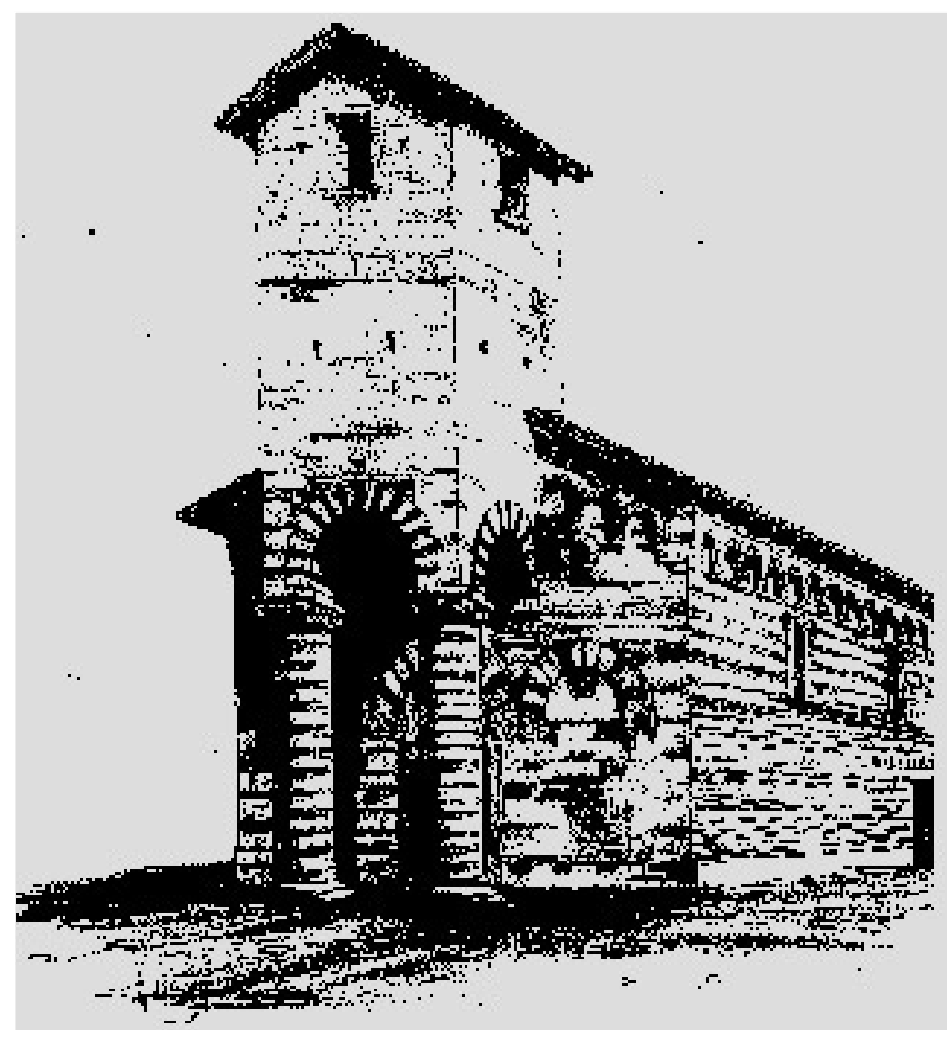

Figura 5. Illustración publicada en el volumen Notes d'un voyage en Corse de Prosper Mérimée (1840).

Corse $^{36}$ de Mérimée, de donde ha sido sacada otra incisión ahora guardada en el Museu di a Corsica a Corte ${ }^{37}$ [Fig. 5]. En esta incisión la altura y la cobertura del campanario corresponden a la de la pintura de Le Clerc, mientras, al contrario, la caña es casi cuadrada, y por lo tanto coherente con las dimensiones del porche. Entre las dos imágenes de la fachada transcurre también una significativa diferencia: si en la pintura de Le Clerc tenemos una perfecta alternancia de hileras blancas y oscuras, en la incisión del Mérimée ellas son como todavía aparecen hoy, en un confuso tablero irregular. La misma perfecta alternancia Le Clerc también la reconduce por cuánto concierne el ábside, haciéndonos poner por lo tanto el problema si no se liberan de una simplificación estética querida por el dibujante, o bien de una reconstrucción parcial del edificio efectuada durante los unos cincuenta años que separan las pinturas de Le Clerc de la incisión del Mérimée, incluso siendo el esta hipótesis poco probable pero no de excluir.

36 MÉRIMÉE 1840, ilustración no numerada entre las páginas 124 y 125.

37 Corte, Museu di a Corsica, Murato: Église paroissiale Saint Michel, n inv. 92118. 


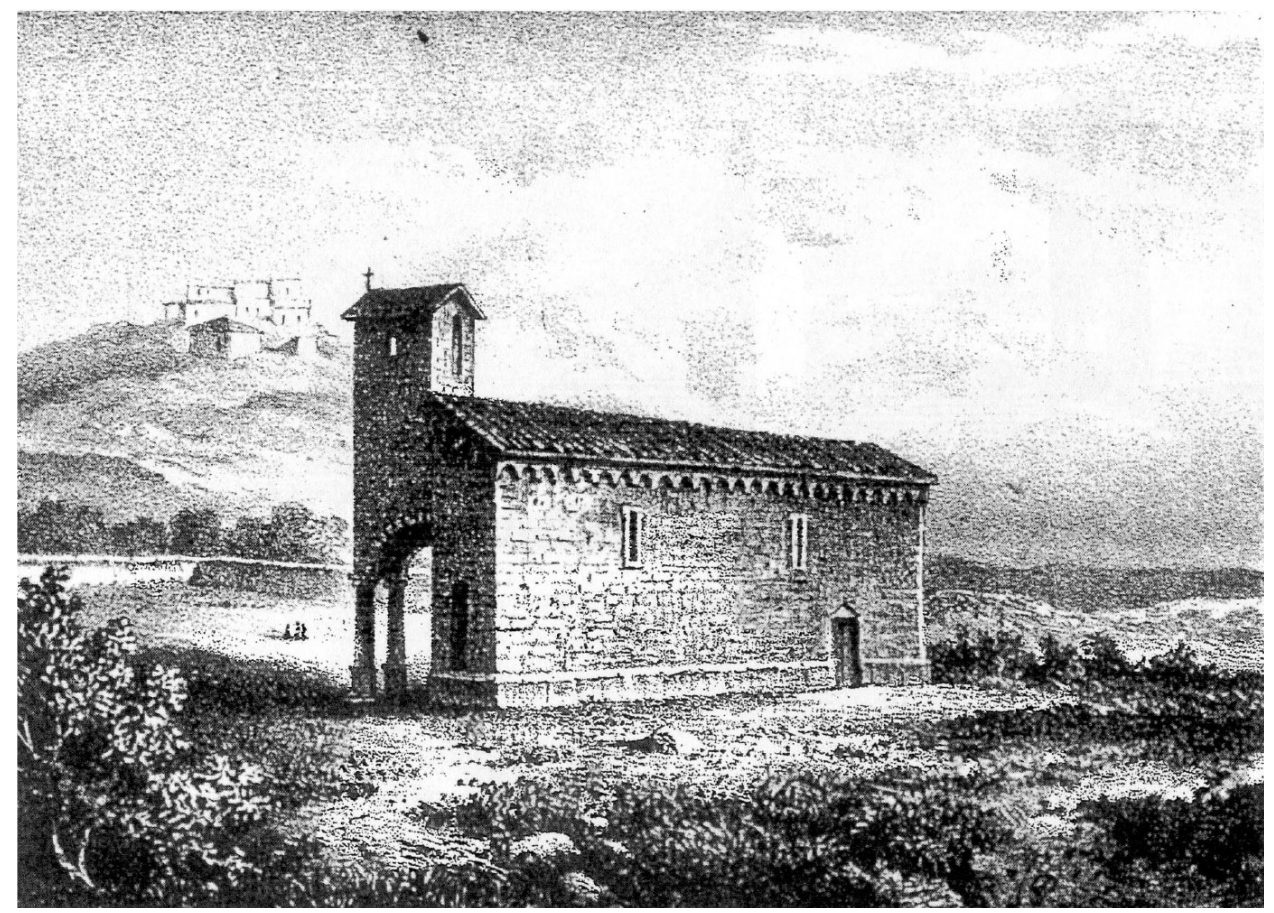

Figura 6. Saint-Michel de Murato, incisión llevada por el volumen Histoire illustrée de la Corse, de Jean-Ange Galletti (1863).

Otros elementos por la restitución del campanario pueden ser sacados por otra incisión, esta vez aparecida en el volumen Histoire illustrée de la Corse, publicado en el 1863 del abbé Jean-Ange Galletti ${ }^{38}$. La incisión [Fig. 6], aunque en una perspectiva falsa, nos ofrece la vista de los dos lados faltantes a nuestra reconstrucción del campanario, el lado a sur y al reverso, confirmando que, hasta el 1863 al menos, el campanario tuvo una altura muy reducida con respecto de aquel actual, una caña más estrecha y una serie de pequeñas ventanas sobre cada lado además de un tejado en declive. Gracias a estos elementos ahora podemos arriesgar una reconstrucción gráfica [Fig. 7] de como fue el campanario antes de su "restauración" al final del siglo XIX, hipotizando una altura de unos 10 metros del suelo contra los actuales 15 metros, y una caña no perfectamente cuadrada, pero más corta a los lados, visiblemente más esbelta que aquella actual.

La restitución enseña por lo tanto una torre de fachada imponente, pero más en línea con las proporciones de la fachada, que acompaña el perfil a salientes del frontón y más conforme a la estereometría del entero edificio, en que se abren ventanas de pequeñas dimensiones, pero que quizás puedan resultar posteriores al período románico. No es en todo caso que excluir la hipótesis que también este campanario sea el resultado de una

38 GALLETTI, 1863. 


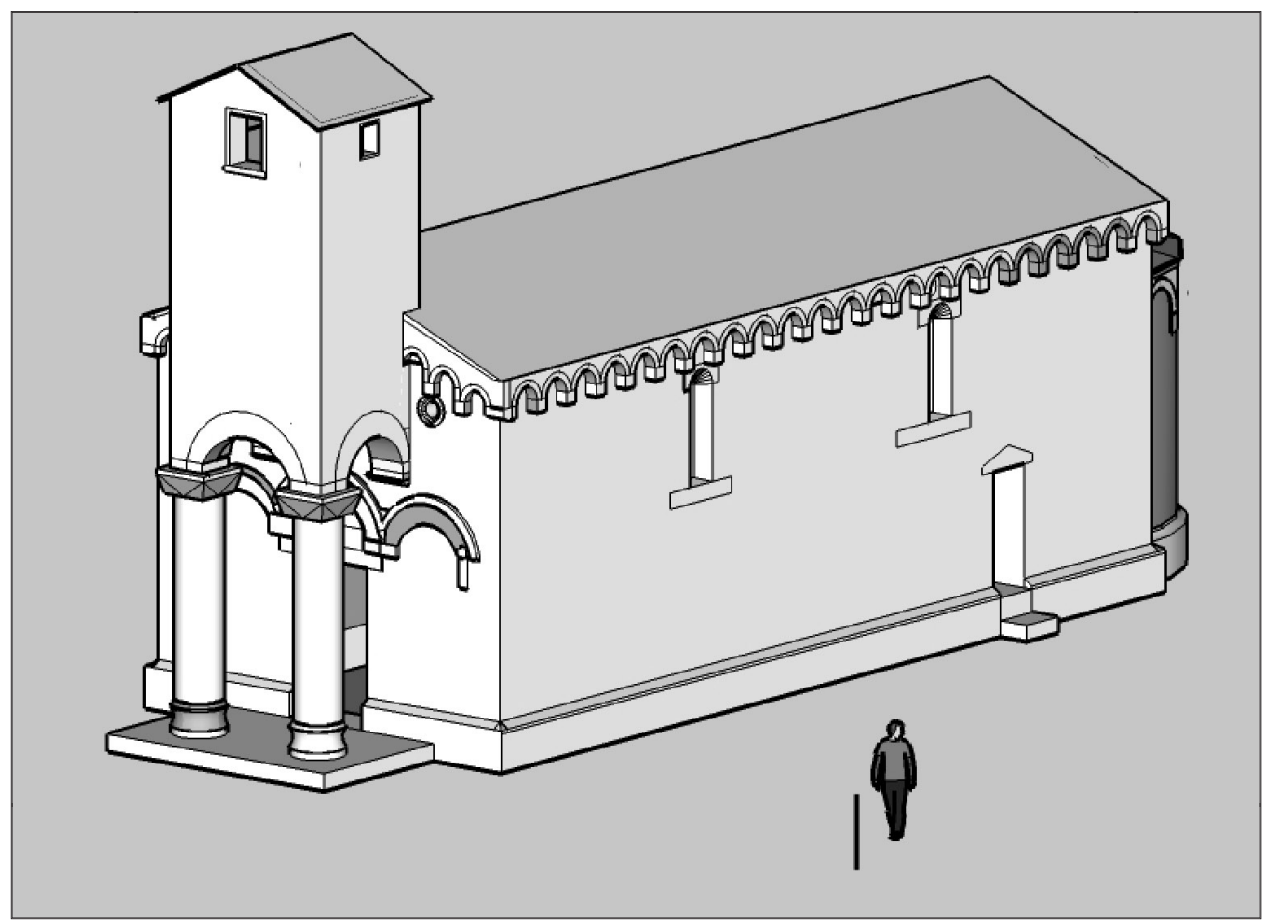

Figura 7. Restitución gráfica del campanario de San Michele de Murado antecedente a la restauración del fin del siglo XIX: fachada y lado sur.

reconstrucción post-románica, sin embargo la restitución enseña el edificio muy parecido a la situación de la torre de fachada de dos iglesias del Lacio meridional, la abadía de Santa Maria de Correano en los alrededores de Ausonia (tercera década siglo XI), y lo abadengo de Santa Maria de Castagneto a Maranola cerca de Formia (mitad siglo XI) ${ }^{39}$, ambas con torre axial en fachada elevada sobre un porche igualmente abierto sobre tres lados. De todas formas, la elección de esta planta comporta "una voluntad, quizás del cliente, más que de las maestranzas, de imitar algún modelo continental, conocido por calles que al momento no es tampoco posible prefigurar" 40.

Todavía queda entender el por qué de una tal intervención de restauración sobre una parte del edificio que parece no necesitara de medidas tan drásticas dadas sus buenas condiciones. Una decisión del género podría explicarse en cambio con el revival medieval que se difunde en toda Europa, de la mitad del siglo XIX y que en Francia ve protagonista al historiador del arte y restaurador Viollet-Le-Duc, del 1845 encargado por el mismo Mérimée, de la restauración de la iglesia gótica de Notre-Dame a París. La intervención sobre Notre-Dame vino practicada de Viollet-Le-Duc siguiendo su teoría 
de "pureza estructural": todo lo que no era medieval fue eliminado implacablemente, mientras las partes faltantes fueron reconstruidas según los modelos originarios, pero en falta de documentos, sobre la base de deducciones y comparaciones, a menudo llegando a reales invenciones, como fue para la grande aguja de la catedral parisiense. Este ejemplo puede ser confrontado, muy en pequeño, con el caso de San Michele de Murato: la torre de fachada tan simple y sosegada en sus dimensiones pudo ser aparecida poco medieval a los ojos de algunos histórico o arquitectos mojados en las enseñanzas de Viollet-Le-Duc, siguiendo sus instrucciones ("Restaurar un edificio no es conservarlo, arreglarlo o rehacerlo, es restablecerlo en un estado de plenitud que puede no haber existido nunca en un dato tiempo", se sintió lícito a "corregir" forma y altura de el en modos más conformes a lo pintoresco y al neomedievalismo dominante.

\section{BIBLIOGRAFÍA}

ARU 1908: Carlo Aru, Chiese pisane di Corsica. Contributo alla storia dell'architettura romanica, Roma, Emanno Loescher, 1908.

BETTI 1999: Fabio Betti, "Da Subiaco a Montecassino. Origine e diffusione della torre di facciata in alcuni edifici religiosi protoromanici del Lazio meridionale", in Arte d'Occidente, temi e metodi. Studi in onore di Angiola Maria Romanini, 1, Roma, Sintesi Informazione, 1999, pp. 71-81.

CANCELLIERI 1994: Jean-André Cancellieri, "Corsica", in Enciclopedia dell'arte medievale, V, Roma, Istituto della Enciclopedia Italiana, 1994, pp. 352-359.

CORONEO 1993: Roberto Coroneo, Architettura romanica dalla metà del Mille al primo '300 = Storia dell'arte in Sardegna, Nuoro, Ilisso, 1993.

CORONEO 2006: Roberto Coroneo, Chiese romaniche della Corsica, Architettura e Scultura (XI-XIIIsecolo), Cagliari, Edizioni AV, 2006.

CORONEO, SERRA 2004: Roberto Coroneo, Renata Serra, Sardegna preromanica e romanica, Milano, Jaca Book; Cagliari, Wide, 2004.

Corsica Christiana 2001: Corsica Christiana. 2000 ans de christianisme, 1-2, catalogo della mostra(Corte, Musée de la Corse, 29 luglio-30 dicembre2001), Corte, Collectivité Territoriale de Corse, 2001.

DELOGU 1964: Raffaello Delogu, Pistoia e la Sardegna nella architettura romanica, Pistoia, Ente provinciale per il turismo, 1964, pp. 84-98, estr. da: "Il romanico pistoiese nei suoi rapporti con l'arte romanica dell'occidente", 1964.

GALLETTI 1863: Jean-Ange Galletti, Histoire illustrée de la Corse (rist. anast. dell'ed. Paris, Pillet, 1863), Marseille, Laffitte Reprints, 1972.

ISTRIA 2002: Daniel Istria, “Le château, l'habitat e l'église dans le Nord de la Corse aux XIIe-XIIIe siècles”, in Mélanges de l'École Française de Rome, Moyen Âge, 114, 2002, 1, pp. 227-301.

ISTRIA 2005: Daniel Istria, Pouvoirs et fortifications dans le Nord de la Corse. XIe-XIVe siècle, Ajaccio, Alain Piazzola, 2005.

MÉRIMÉE 1840: Prosper Mérimée, Notes d'un voyage en Corse [1840], ristampa anastatica Ajaccio, La Marge, 1997. 
MORACCHINI-MAZEL 1967a: Geneviéve Moracchini-Mazel, Les Églises Romanes de Corse, I-II, Paris, C.Klincksieck,1967.

MORACCHINI-MAZEL 1967b: Geneviéve Moracchini-Mazel, Les monuments paléochrétiens de la Corse, Paris, C.Klincksieck,1967.

MORACCHINI-MAZEL 1972: Geneviéve Moracchini-Mazel, Corse romane, La Pierrequi-vire, Zodiacque, 1972.

MORACCHINI-MAZEL 2004: Geneviève Moracchini-Mazel, Corsica Sacra, I, IVe- $X^{e}$ siècles, Portovecchio, A Stamperia, 2004.

MORETTI, STOPANI 1982: Italo Moretti, Renato Stopani, La Toscana = Italia Romanica, 5, Milano, Jaka Book, 1982.

ORSOLINI 2003: Joseph Orsolini, L'art de la fresque in Corse de 1450 à 1520, Ajaccio, Editions du parc naturel régional de Corse, 2003.

PINAULT SøRENSEN 2003: Pinault-Sørensen 2003: Madeleine Pinault-Sørensen, "Témoignages de l'architecture italienne en Corse à travers quelques dessins français du XVIIIe siècle", in Bulletin de l'Association des Historiens de l'Art Italinen, 9, 2002-2003, pp. 121-131.

SALMI 1927: Salmi 1927: Mario Salmi, L'architettura romanica in Toscana, MilanoRoma, Bestetti Tumminelli, 1927.

SCALFATI 1971: Silio P.P. Scalfati, Carte dell'Archivio della Certosa di Calci, II (11001150), Thesaurus Ecclesiarum Italiae, VII, Roma, Edizioni di Storia e Letteratura, 1971.

UGHELLI 1717-1722: Ferdinando Ughelli, Italia Sacra / auctore Ferdinando Ughello. - Rist. anast. - Sala Bolognese: Arnaldo Forni phototypice excudente, stampa 19721989. - 10 v. (Ripr. facs. dell'ed.: Venetiis: apud Sebastianum Coleti, 1717-1722).

VALERY 1837: Valery [Antoine-Claude Pasquin], Voyages en Corse, à l'Ile d'Elbe et en Sardaigne, I, Paris, Libraire de L. Bourgeois-Maze, 1837. 